\title{
Effect of Voltage and Distance on Synthesis of Boehmite Nanofibers with PVP by the Electrospinning Method
}

\author{
Leila Sharifi ${ }^{1, *}$, Farnaz Assa ${ }^{1}$, Hossein Ajamein ${ }^{1}$, Seyyed Hossein Mirhosseini ${ }^{1}$ \\ ${ }^{1}$ Academic Center for Education, Culture and Research, Yazd Branch, Iran \\ sharifi.leila.jd@gmail.com,farnaz_assa@yahoo.com,h.ajamein@gmail.com, \\ mirhosseini.jd@gmail.com
}

\begin{abstract}
In this paper the effect of different voltages and distances on quality of boehmite nanofibers fabricated by the electrospinning method was investigated. For this purpose, boehmite nanoparticles were synthesized using aluminum nitrate precursor and ammonia. The resulted product was electrospined by applying the voltage range of 8-14 kV. Various analyses such as XRD, SEM and nanofibers diameter size distribution were applied to study the characteristic properties of boehmite nanoparticles and nanofibers. The results of these analyses represented that electrospinning of boehmite nanoparticles with specific surface area of $256 \mathrm{~m}^{2} / \mathrm{gr}$ and crystallite size of $7 \mathrm{~nm}$ by applying optimum voltage of 10 $\mathrm{kV}$ and distance of $10 \mathrm{~cm}$, can produce homogeneous boehmite nanofibers without any nodes. Also, by increase of the applied voltage in the electrospinning process, the diameter of produced nanofibers increased, but on the other hand fiber uniformity also increased.
\end{abstract}

Keywords: Bohemite, Electrospinning, Voltage, Polyvinylpyrrolidone, Nanofibers

\section{Introduction}

The fiber spinning process uses electrostatic forces known as electrospinning. This process was first observed in 1914 by Riley and Zeleny. In recent decades, electrospinning not only because of variations in spinning of different polymeric fibers, but also due to production of fibers in sub-micron range has attracted much attention [1, 2]. These fibers despite of conventional fibers have micro pores and higher specific surface area, and are used in the catalyst, tissue scaffolds, protective clothing, filtration, optical and electrical components [3, 4].

Generally, the electrospinning device consists of three parts: a high-voltage source, cutting noodles (the spray) and collector (usually aluminum foil). In the non-mechanical electrostatic method a high voltage electric field is applied to charge droplet surface of the polymer solution to direct the liquid jet from a spinner [5,6]. The formed liquid jet becomes longer and thinner until it will be solid and accumulates on the collector that can be a smooth plate (usually aluminum) or a rotating roller [7, 8]. Electrospun nanofibers can be used in a wide variety of different areas including tissue engineering scaffolds, controlled drug delivery, filtering, protective clothes, sensors and energy storage and conversion. In general, variety of factors affect on electrospun nanofibers which divided into three categories: system parameters, process parameters and environmental parameters. These factors can be influenced directly on the morphology of spun fibers

\footnotetext{
* Corresponding author: Leila Sharifi

Address: Academic Center for Education, Culture and Research, Yazd Branch, Iran

E-mail Addredd: sharifi.leila.jd@gmail.com

Tel.: +98 (35) 36241085

Fax: +98 (35) 36292962
} 
$[11,12]$. The system parameters can be exampled such as the viscosity of the solution or melt, concentration, conductivity, surface tension, molecular weight of polymeric raw material and etc. [13, 14]. Also, applied voltage power, flow velocity, the distance between the needle tip and the collector plate (air gap), surrounding environment, temperature and humidity of spinning chamber, status of collector plate (moving or static), the diameter of the syringe can be counted as the process parameters [15-17]. Among the mentioned parameters, polymer concentration, viscosity and feed rate directly influence on the diameter of fibers while the effect of solution conductivity, temperature and voltage is opposite. In addition, increase of surface tension leads to instability of produced fibers $[18,19]$.

The ceramic nanofibers electrospinning process consists of three main steps including preparation of spinning solution, electrospinning in optimum conditions and finally heat treatment (calcination) in order to remove the organic components and to obtain the desired ceramic phase. In the case of composite nanofibers of ceramic and polymer components the calcination step will be omitted [20,21].

Nanofibers can be mainly used in filtration systems due to their advantages like removing of some time consuming steps for example cleaning, recharging filter or the eliminating of hazardous waste. These filters simultaneously remove chemical and biological compounds without any chemical disinfectants and coagulants even in turbid salt water.

Panda et al. prepared alumina nanofibers with different chemical precursors. They used polyvinyl alcohol and polyethylene oxide as polymer agents as well as aluminum acetate and aluminum nitrate as precursors to produce composite nanofibers by the electrospinning method. Sequentially, in order to produce pure alumina nanofibers, the resulted nanofibers were calcined at $900{ }^{\circ} \mathrm{C}$ and $1300{ }^{\circ} \mathrm{C}$ to remove organic materials. Also, they investigated the effect of increasing the alumina content on the morphology of obtained nanofibers by electrospinning of three kinds of solutions with aluminum salt / polymer ratios of 10,50 and 100 percent. The results indicated that nanofibers prepared by the solution containing $50 \%$ alumina were smooth with no nodes despite the sample formed by $10 \%$ alumina. In addition, electrospinning of solution with no polymer content and $100 \%$ alumina was not possible [22].

In another study, Hao et al. synthesized alumina nanofibers through electrospinning using aluminium 2, 4 pentane dianat precursor and a solution of polyacrylonitrile dissolved in dimethylformamide. Then, the nanofibers were calcined at $1000{ }^{\circ} \mathrm{C}$ and were analyzed. The thermal gravimetric results revealed that three weight loss steps could be observed during the heat treatment of prepared nanofibers. The weight loss stage has occurred prior to $175^{\circ} \mathrm{C}$ related to the free solvent release from composite fibers. Then, a significant weight loss occurred at a $314{ }^{\circ} \mathrm{C}$ due to the decomposition of aluminium 2,4 pentane dianat and circularization of nitrile groups of polyacrylonitrile. Finally, the weight loss at $795{ }^{\circ} \mathrm{C}$ is related to the oxidation of carbon and carbon monoxide [23].

Azad et al. synthesized alumina nanofibers by the electrospinning method with aluminum 2, 4 pentane dianat precursor to study the various amount of polyvinylpyrrolidone as polymer agent. After the electrospinning process, the resulting fibers were calcined at different temperatures. Comparing the SEM of composite fibers and pure alumina fibers revealed that both of them had the fibril structure and the fiber diameter was reduced during calcination stage [24].

In the present study, hydrated alumina nanofibers (boehmite) were synthesized in the presence of polyvinylpyrrolidone. Initially for preparation of nanoboehmite, aluminum nitrate and ammonia was used as raw materials. Boehmite nanoparticles with different particle size were synthesized by the precipitation method. In the next step, $8 \%$ wt solution of PVP in ethanol was prepared and then mixed with nanoboehmite and the effect of various voltages on morphology and the diameter of electrospun nanofibers were evaluated. 


\section{Experimental}

\subsection{Materials and Equipment}

In this study, aluminium nitrate nonahydrate $\left(\mathrm{Al}\left(\mathrm{NO}_{3}\right) \cdot 9 \mathrm{H}_{2} \mathrm{O}\right)$ from Samchun Company, South Korea were used as precursor for production of boehmite nanoparticles. Also, ammonia used as the $\mathrm{pH}$ controller and polyvinylpyrrolidone with the molecular weight of 360,000 is used as electrospun polymer. Polyvinylpyrrolidone and ethanol were supplied from of Merck. The electrospinning device used in this study is a syringe pump (Syringe Pump SP1000 model) made by Fanavaran Nanomeghyas company which is shown schematically in Figure 1. All the spinning process was performed at room temperature. The feeding rate of syringe pump was set at $1.0 \mathrm{ml} / \mathrm{hr}$. Voltage of the electrospinning device was controlled between $8-14 \mathrm{kV}$. The distance between the needle and the collector plate was adjusted 8,10 and $12 \mathrm{~cm}$.

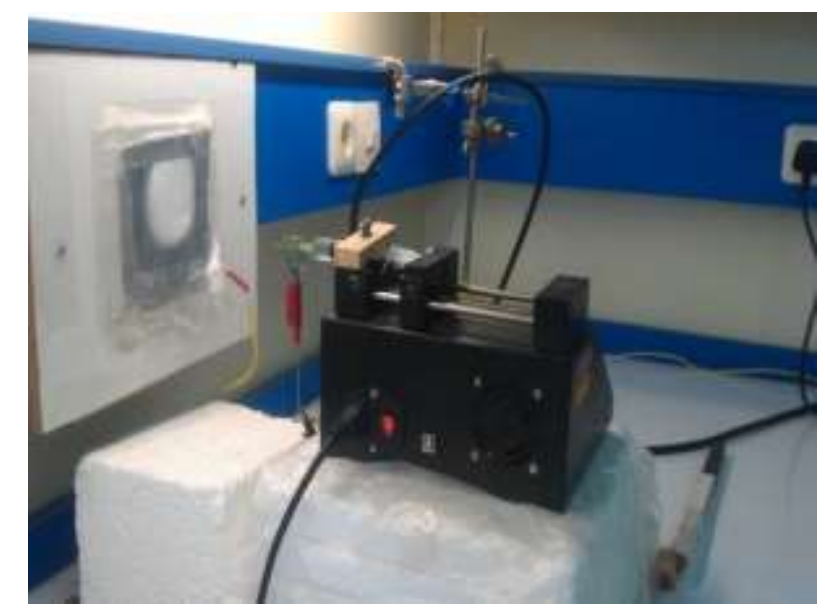

Figure 1. The Electrospinning Device

\subsection{Characteristic Analyzes of Nanofibers}

In order to identify the crystallite phases of prepared nanofibers, an X-ray diffraction device, PW1800 PHILIPS, was used with a wavelength of $1.54^{\circ} \mathrm{A}$. This device uses $\mathrm{Cu}$ $\mathrm{K} \alpha$ radiation coupled to an X-ray tube and works at $30 \mathrm{kV}$ and $40 \mathrm{~mA}$. Joint Committee on Powder Diffraction Standards (JCPDS) were used comparatively to discover crystallite phases. Crystallite size of boehmite was measured using the Scherrer equation as follows:

$t=\frac{0.9 \lambda}{B \cos \theta}$

Where $\mathrm{B}$ is the highest peak width at half height of it in $\mathrm{nm}, \mathrm{t}$ is grains average diameter in $\mathrm{nm}$ and $\theta$ is the scattering angle of the highest peak in radians. By applying the correction ratios related to device error can improve the accuracy of the procedure. $\mathrm{B}_{\mathrm{s}}$ was calculated using zirconia powder peak width with a crystallite size of $27 \mathrm{~nm}$ and $B_{m}$ desired peak width. The obtained $\mathrm{B}$ is placed in the above equation and $\mathrm{t}$ is calculated.

$B^{2}=B_{M}^{2}-B_{S}^{2}$

The scanning electron microscope (SEM) analysis was applied using a StereoScan360 (leica / combridg) device to survey the morphology of resulted nanofibers. The ImageJ software was used for determination of nanofibers diameter. 


\subsection{Boehmite Nanofiber Synthesis Method}

In this paper for the synthesis of boehmite nanofibers by the electrospinning method, a $0.5 \mathrm{M}$ aqueous solution of aluminum nitrate was prepared. Then, a white precipitate was formed by increasing $\mathrm{pH}$ to 8 by addition of ammonia. For the complete precipitation process the solution was aged for 20 hours at $80^{\circ} \mathrm{C}$. The resulted precipitate was dried at $60{ }^{\circ} \mathrm{C}$. Then, the prepared boehmite nanoparticles were mixed with polyvinylpyrrolidone to achieve the feed for the electrospinning process. The electrospinning process was taken place under different voltages and the distance between the needle and the collector plate. For this purpose, a solution of $8 \%$ wt. of polyvinylpyrrolidone in ethanol was prepared and $10 \%$ wt. of boehmite nanoparticles was added to the solution. The resulted mixture spilled into a $10 \mathrm{ml}$ plastic syringe and the distance from the tip of the needle to the aluminum plate collector was adjusted. Electrical connection is established and after setting the solution flow rate on the value of $1 \mathrm{ml} / \mathrm{h}$, to find the optimum voltage, the prepared sol was electrospun in 8-14 voltage and primary nanofibers collected on the surface of aluminum. Electrospinning steps are schematically depicted in Figure 2.

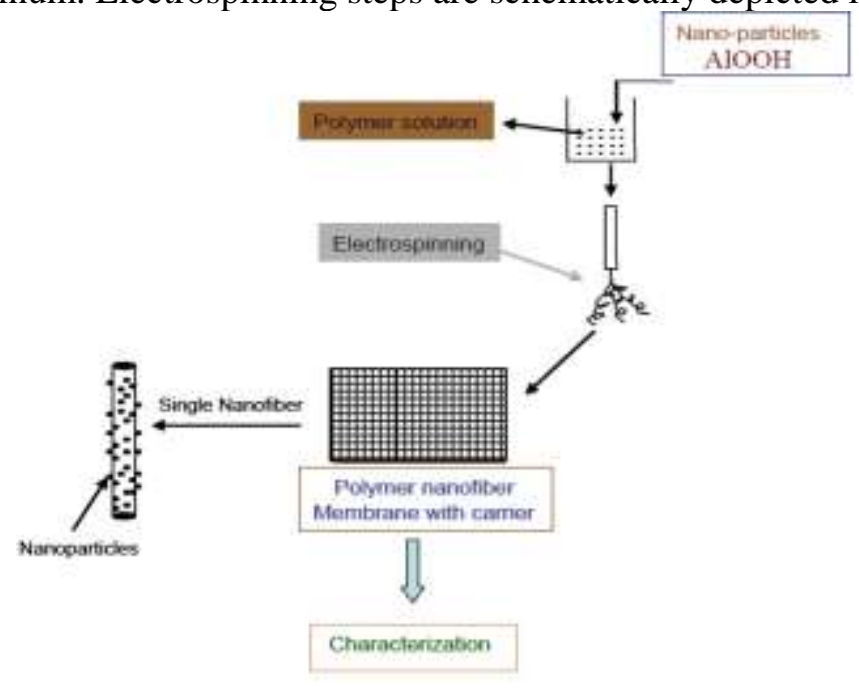

\section{Figure 2. Schematic of Boehmite Nanofibers/ PVP Synthesis Steps via the Electrospinning Process}

\section{Results and Discussion}

In this paper, the effect of voltage on the structural properties of boehmite nanofibers synthesized by the electrospinning method was demonstrated. As mentioned, boehmite nanoparticles using aluminum nitrate precursor by the precipitation method was synthesized and characterized in terms of crystallinity by X-ray diffraction which is shown in Figure 3. 


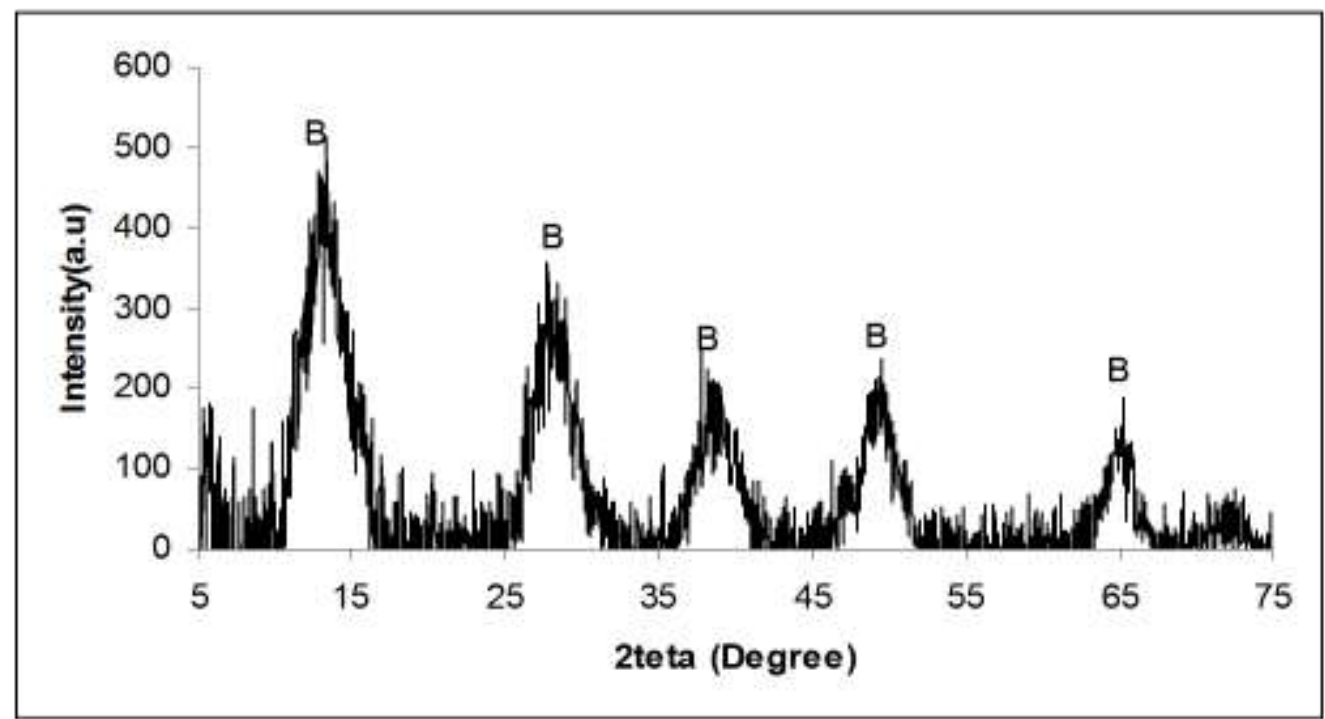

Figure 3. X-ray Diffraction Pattern of Boehmite at a Temperature of $80^{\circ} \mathrm{C}$ and $\mathrm{pH} 8$

The boehmite characteristic peaks according to JCPDS No.: 01-072-0359 in $2 \theta$ of $14.46^{\circ}, 28.18^{\circ}, 33.38^{\circ}, 48.93^{\circ}$ and $64.32^{\circ}$ are easily recognized [25]. These peaks represent the boehmite crystals were formed appropriately. According to the Scherrer formula, the crystal size of formed boehmite is approximately $7 \mathrm{~nm}$. Also, from BET analysis it was found out the specific surface area of synthesized nano boehmite equal to $256 \mathrm{~m}^{2} / \mathrm{gr}$. Surface morphology of synthesized boehmite nanoparticles was investigated by FESEM analysis according to Figure 4.

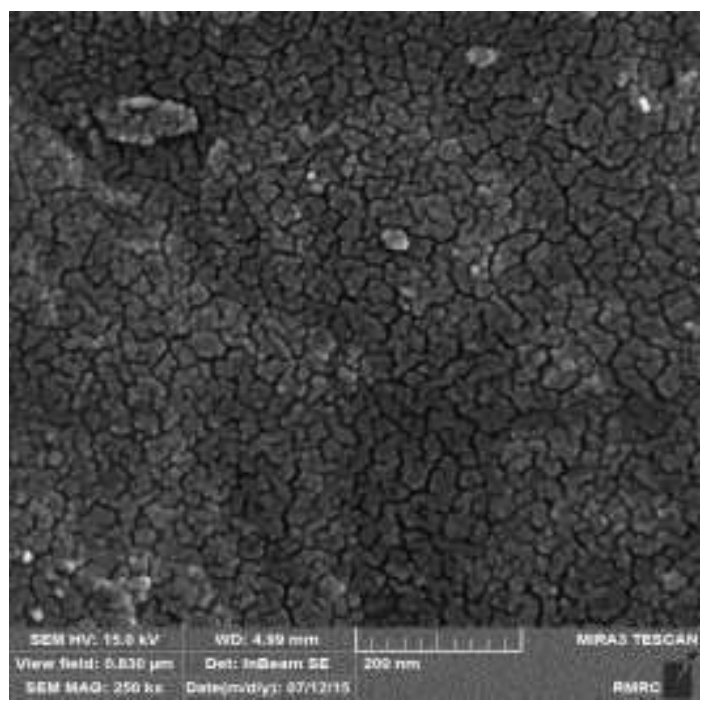

\section{Figure 4. The Field Emission Electron Microscope Image of Synthesized Nano Boehmite Sample}

In the next stage synthesized nano boehmite powder was mixed with an $8 \%$ wt. polyvinylpyrrolidone solution and boehmite nanofibers produced by using an electrospinning device. To investigate the effect of applying voltage on characterizations of prepared nanofibers, it was changed from 8 to $14 \mathrm{kV}$. In order to evaluate the quality of prepared nanofibres, field emission scanning electron microscopy analysis as well as the 
fibers diameter analysis by the ImageJ software were employed and their results are represented in the below figures.
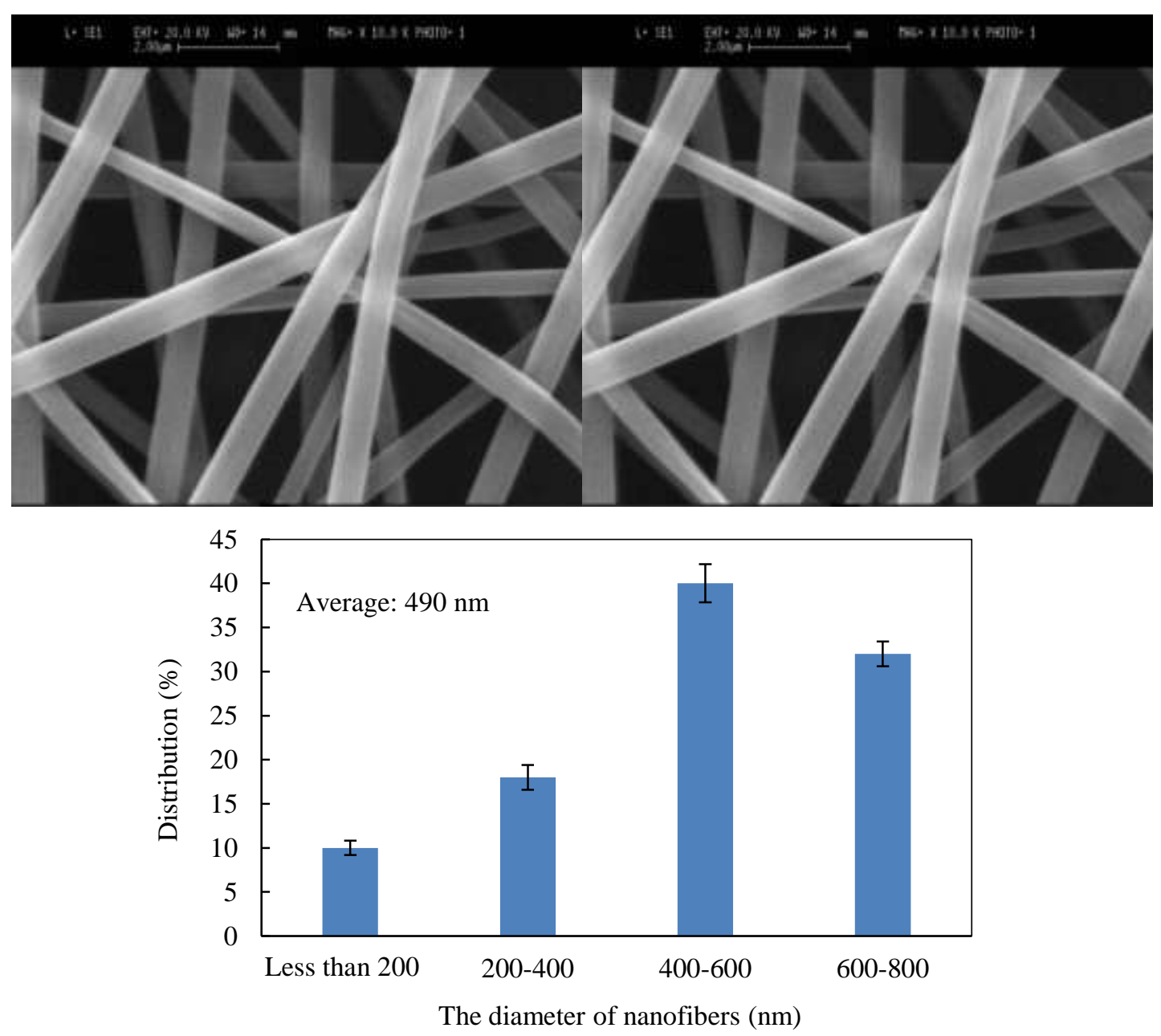

\section{Figure 5. Images of SEM analysis and Size Distribution of the Produced Nanofibers Diameter by 8 kV Voltage}

Generally, it can be concluded that the solution of nano boehmite and PVP had well spinning ability without nodes and prepared smooth and continuous nanofibers. At low voltages, electrical field did not have enough power to pull the fibers and this phenomenon promoted the nanofibers diameter and in some cases nodes were even formed. However, the number of nodes were few and presented as roughness of fibers. By increasing the voltage to $10 \mathrm{kV}$, more homogeneous fibers with lower diameters were formed so that the mean diameter decreased from 490 to $440 \mathrm{~nm}$. This is because of enhancement of liquid jet formation rate to the collector plate due to influence of higher voltage on domination the solution forces. 

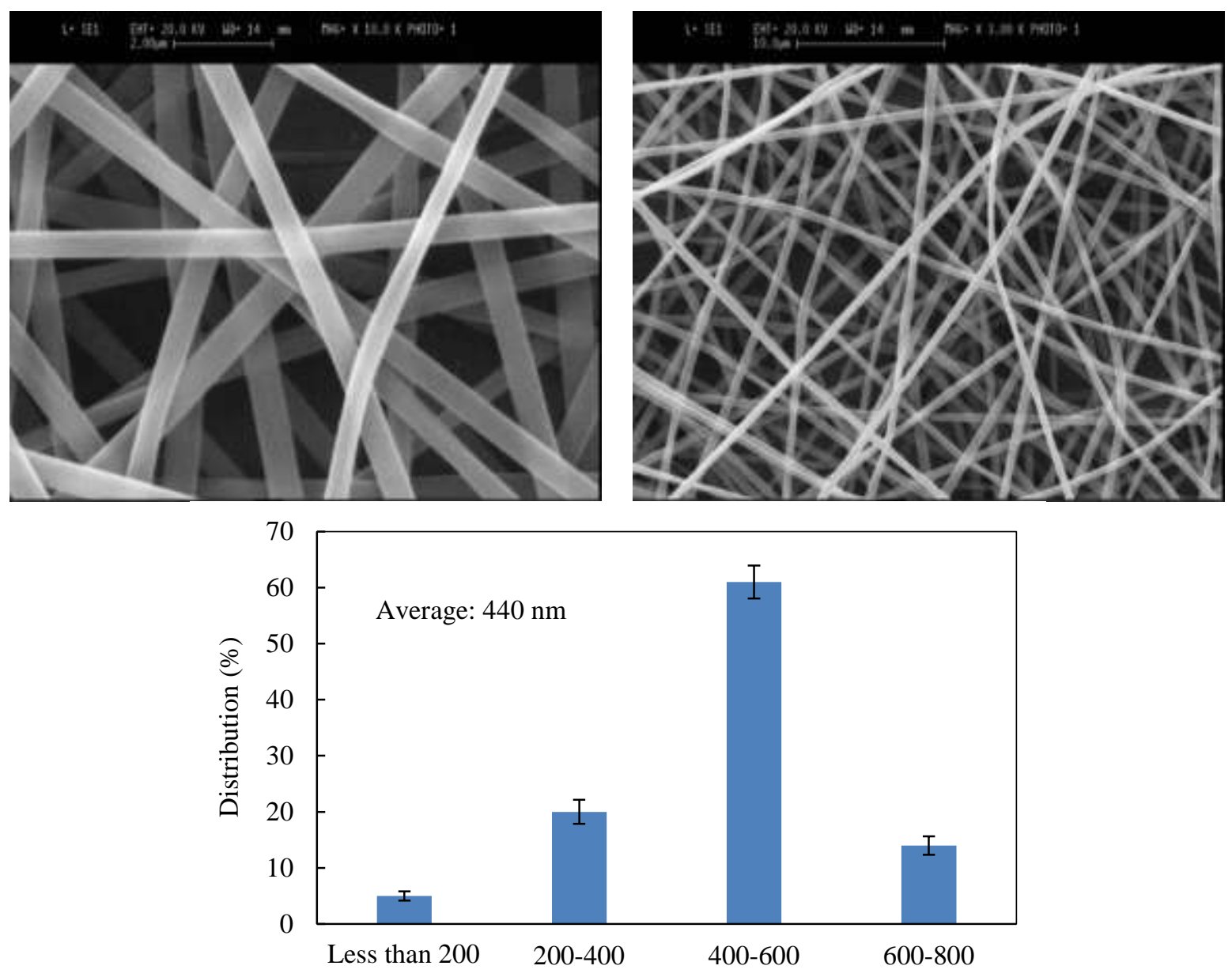

The diameter of nanofibers (nm)

Figure 6. Images of SEM Analysis and Size Distribution of the Produced Nanofibers Diameter by 10 kV Voltage

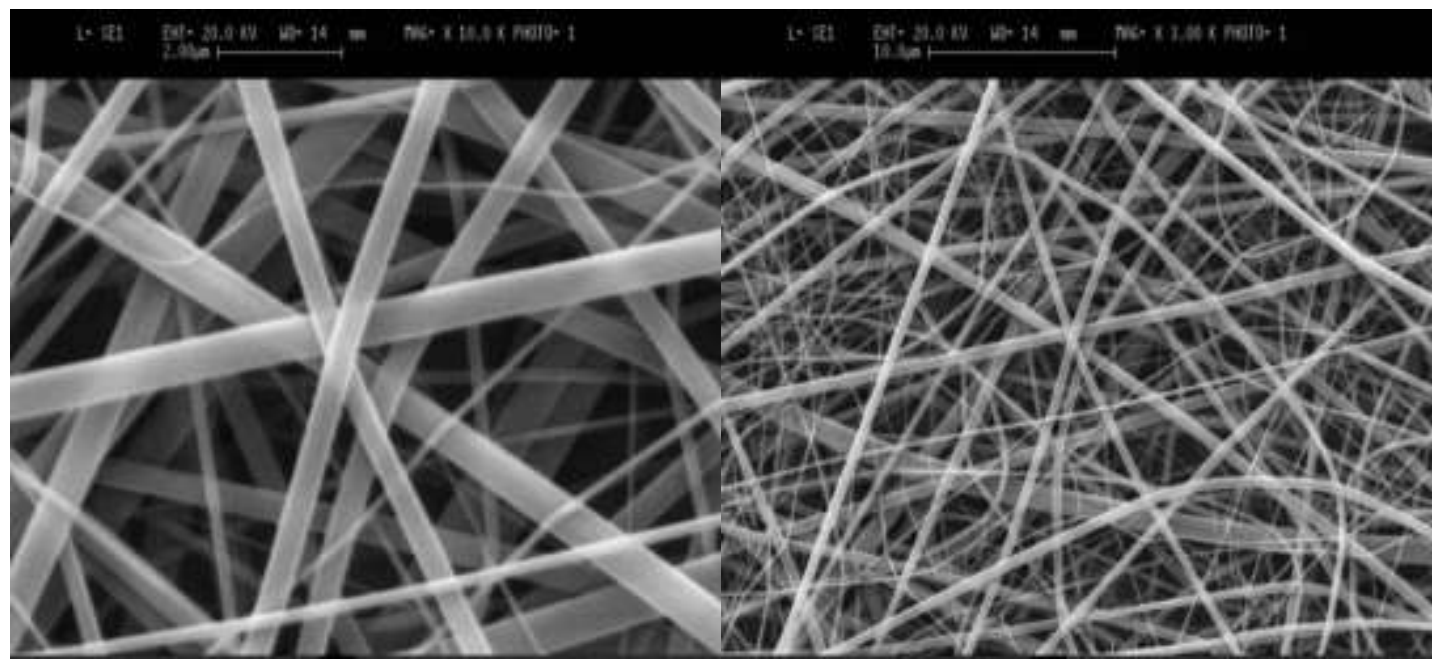




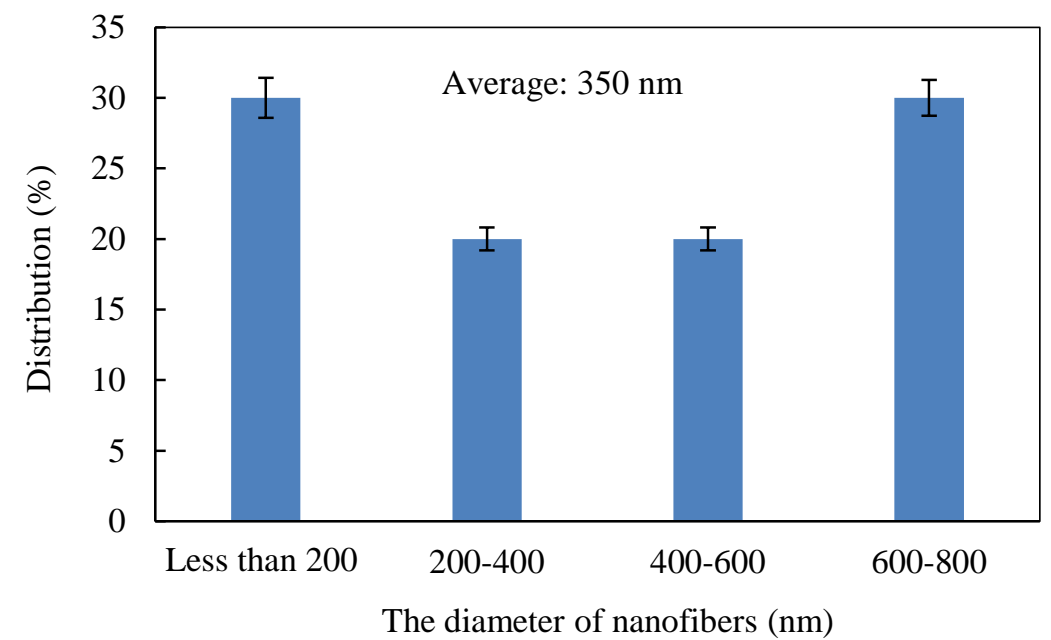

\section{Figure 7. Images of SEM Analysis and Size Distribution of the Produced Nanofibers Diameter by 12 kV Voltage}

By increasing the voltage, the static force which can overcome the surface tension of the droplet emerging from the tip increased and the velocity of converting droplet to the fiber consequently increased which led to thinner nanofibers. By increasing the voltage up to $12 \mathrm{kV}$, the diameter of nanofibers increased due to unlimited existence of solution from the syringe tip. Also, in high voltages multi jets of solution instead of one jet formed on the tip of syringe which resulted non-uniform fibers according to their diameters. In this case, the range of nanofibers diameter varied between 800-100 nm. By increasing the voltage to $14 \mathrm{kV}$, the diameter size distribution range became broader, so that it reached to $50-1000 \mathrm{~nm}$. Therefore, results show that the optimal voltage for preparation of boehmite nanofibers via the electrospinning process is $10 \mathrm{kV}$.

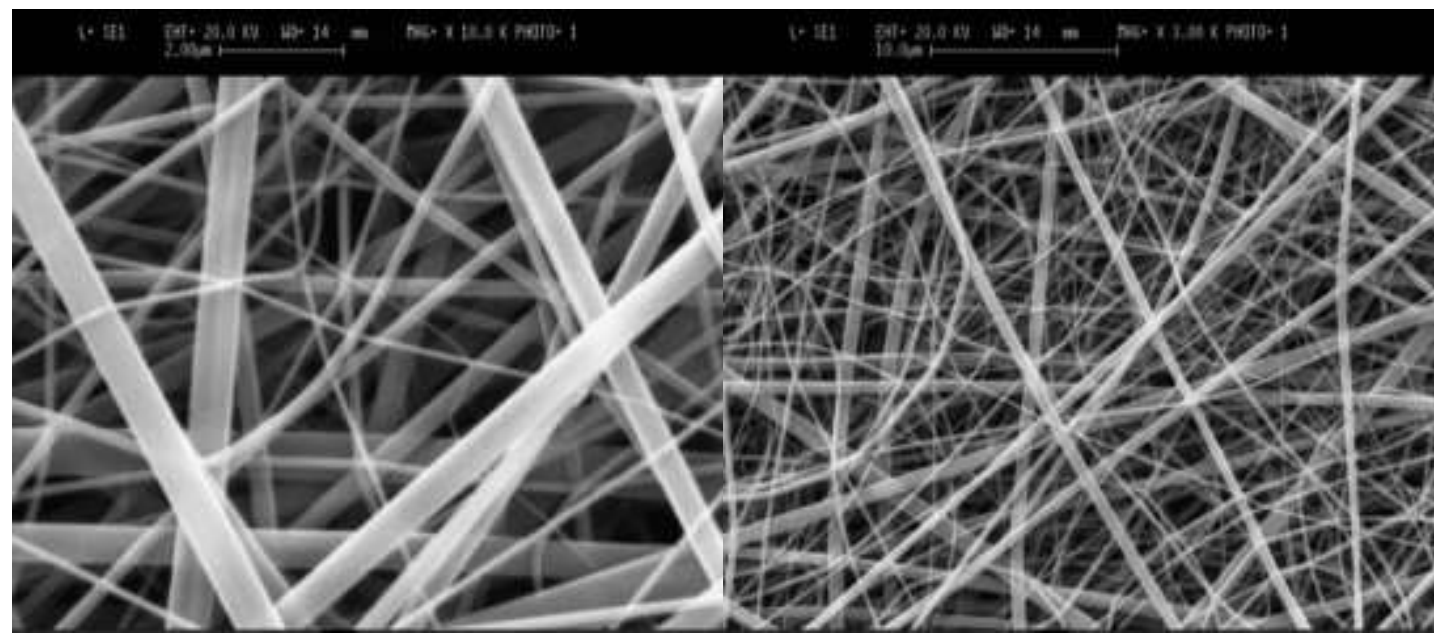




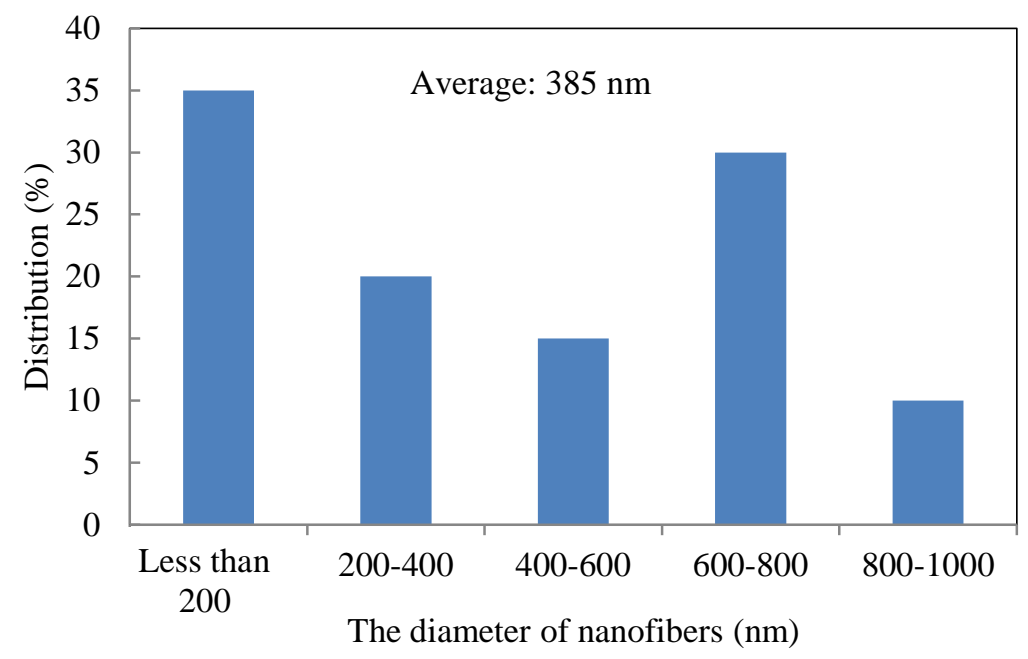

\section{Figure 8. Images of SEM analysis and Size Distribution of the Produced Nanofibers Diameter by 14 kV Voltage}

The effect of distance between the syringe tip and collector plate on the size and morphology of the nanofibers was studied. At small distances, nanofibers did not spend enough time to reach the collector plate and the solvent did not have enough time to exit and to combine with main materials and remained in structures. So, the diameter of nanofibers increased and nudes could be created in the fibers' structure that created inappropriate properties in nanofibers. However, the number of nudes was low and presented as roughness of fibers. This problem disappears by increasing the optimum distance. By enhancement of distance up to $10 \mathrm{~cm}$, more time is given to solvents to exit and the fibers formed more uniform. In addition, more uniform distribution of the fibers diameter is obtained. When this distance enhanced up to $12 \mathrm{~cm}$, the effect of voltage decreased and the strength of the electric field for solutions withdrawal of the needle reduced and thus, the fiber diameter increased. So, the diameter of the nanofibers increased from $490 \mathrm{~nm}$ to $550 \mathrm{~nm}$. Thus, the optimum distance between the collector plate and the needle in the optimum voltage $(10 \mathrm{kv})$ is $10 \mathrm{~cm}$. The results of SEM analysis are shown in Figure 9.

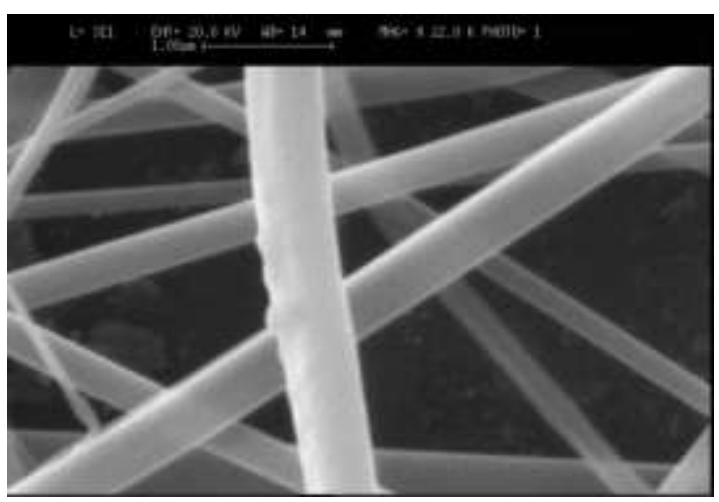



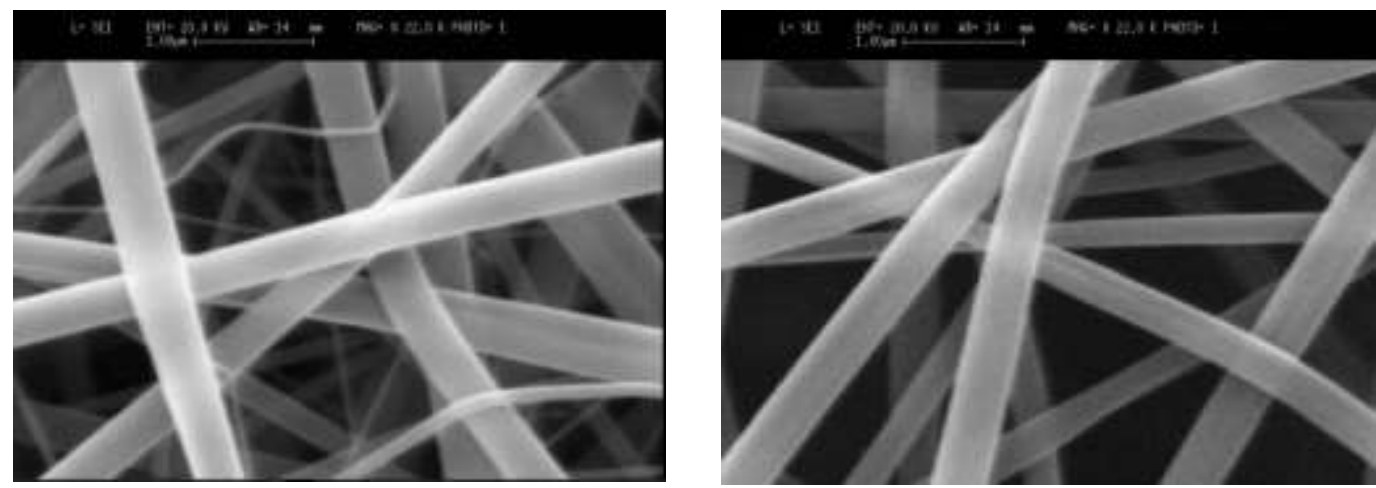

Figure 9. SEM Images of Boehmite Nanofibers in the Air Gaps 8, 10 and 12 at $10 \mathrm{kv}$

\section{Conclusions}

The purpose of the present paper was to prepared boehmite nanofibers by electrospinning method from nano boehmite powder which synthesized by aluminum nitrate precursor and ammonia precipitator was prepared. The boehmite nanoparticles were mixed in an $8 \%$ wt solution of polyvinylpyrrolidone and electrospun with different voltages and air distances. The structural analysis results showed that synthetic boehmite nanoparticles have crystals equal to $7 \mathrm{~nm}$ and specific surface area equal to 256 square $\mathrm{m}^{2} / \mathrm{gr}$, respectively. Also, by increase of the applied voltage in the electrospinning process, the diameter of produced nanofibers increased, but on the other hand fiber uniformity also increased. In this case, the optimum value for applied voltage and the air gap were achieved $10 \mathrm{kV}$ and $10 \mathrm{~cm}$, respectively.

\section{References}

[1] E. Storti, M. Roso, M. Modesti, C. G. Aneziris, P. Colombo, "Preparation and morphology of magnesium borate fibers via electrospinning", Journal of European Ceramic Society, vol. 36 , no. 10, (2016) pp. 2593-2599.

[2] A. Moheman, M. S. Alam, A. Mohammad, "Recent trends in electrospinning of polymer nanofibers and their applications in ultra thin layer chromatography", Advances in Colloid and Interface Science, vol. 229, (2016) pp. 1-24.

[3] F. E. Ahmed, B. S. Lalia, R. Hashaikeh, "A review on electrospinning for membrane fabrication: Challenges and applications", Desalination, vol. 356, (2015) pp. 15-30.

[4] P. Milanović, M. Dimitrijević, R. Jančić Heinemann, J. Rogan, D. B. Stojanović, A. Kojović, R. Aleksić, "Preparation of low cost alumina nanofibers via electrospinning of aluminium chloride hydroxide/poly (vinyl alcohol) solution”, Ceramic International, vol. 39, no. 2, (2013) pp. 2131-2134.

[5] S. Almuhamed, M. Bonne, N. Khenoussi, J. Brendle, L. Schacher, B. Lebeau, D. C. Adolphe, "Electrospinning composite nanofibers of polyacrylonitrile/synthetic Na-montmorillonite", Journal of Industrial Engineering Chemistry, vol. 35, (2016) pp. 146-152.

[6] V. Maneeratana, W. M. Sigmund, "Continuous hollow alumina gel fibers by direct electrospinning of an alkoxide-based precursor", Chemical Engineering Journal, vol. 137, no. 1, (2008) pp. 137-143.

[7] C. Peng, P. Liu, J. Hu, T. Hua, Y. Shen, B. Zhao, G. Tang, "Preparation of uniaxially aligned mullite ceramic fibers by electrospinning", Colloids and Surfaces A: Physicochemical and Engineering Aspects, vol 457, (2014) pp. 1-7.

[8] L. B. Modesto-López, R. J. Chimentão, M. G. Álvarez, J. Rosell-Llompart, F. Medina, J. Llorca, "Direct growth of hydrotalcite nanolayers on carbon fibers by electrospinning", Applied Clay Science, vol. 101, (2014) pp. 461-467.

[9] P. Moradipour, F. Dabirian, L. Rajabi, A. A. Derakhshan, "Fabrication and characterization of new bulky layer mixed metal oxide ceramic nanofibers through two nozzle electrospinning method", Ceramics International, vol. 42, no. 12, (2016) pp. 13449-13458.

[10] J. Shen, Z. Li, Y. -n. Wu, B. Zhang, F. Li, "Dendrimer-based preparation of mesoporous alumina nanofibers by electrospinning and their application in dye adsorption", Chemical Engineering Journal, vol. 264, (2015) pp. 48-55. 
[11] M. Vahtrus, M. Umalas, B. Polyakov, L. Dorogin, R. Saar, M. Tamme, K. Saal, R. Lõhmus, S. Vlassov, "Mechanical and structural characterizations of gamma- and alpha-alumina nanofibers", Materials Characterization, vol. 107, (2015) pp. 119-124.

[12] F. Li, Z. Kang, X. Huang, G. -J. Zhang, "Fabrication of zirconium carbide nanofibers by electrospinning”, Ceramics International, vol. 40, no. 7, (2014) pp. 10137-10141.

[13] X. Tang, Y. Yu, "Electrospinning preparation and characterization of alumina nanofibers with high aspect ratio", Ceramics International, vol. 41, no. 8, (2015) pp. 9232-9238.

[14] P. Liu, Y. Zhu, J. Ma, S. Yang, J. Gong, J. Xu, "Preparation of continuous porous alumina nanofibers with hollow structure by single capillary electrospinning", Colloids and Surfaces A: Physicochemical and Engineering Aspects, vol. 436, (2013) pp. 489-494.

[15] H. Shao, X. Zhang, S. Liu, F. Chen, J. Xu, Y. Feng, "Preparation of pure iron nanofibers via electrospinning", Materials Letters, vol. 65, no. 12, (2011) pp. 1775-1777.

[16] W. Yang, Y. Zhang, C. Liu, J. Jia, "Dual-doped carbon composite for efficient oxygen reduction via electrospinning and incipient impregnation", Journal of Power Sources, vol. 274, (2015) pp. 595-603.

[17] Q. Wang, W. -L. Song, L. -Z. Fan, Y. Song, "Facile fabrication of polyacrylonitrile/alumina composite membranes based on triethylene glycol diacetate-2-propenoic acid butyl ester gel polymer electrolytes for high-voltage lithium-ion batteries", Journal of Membrane Science, vol. 486, (2015) pp. 21-28.

[18] C. Peng, J. Zhang, Z. Xiong, B. Zhao, P. Liu, "Fabrication of porous hollow $\gamma-\mathrm{Al}_{2} \mathrm{O}_{3}$ nanofibers by facile electrospinning and its application for water remediation", Microporous and Mesoporous Materials, vol. 215, (2015) pp. 133-142.

[19] S. Liu, X. Zhang, H. Shao, J. Xu, F. Chen, Y. Feng, "Preparation of $\mathrm{MoS}_{2}$ nanofibers by electrospinning", Materials Letters, vol. 73, (2012) pp. 223-225.

[20] A. Mahapatra, B. G. Mishra, G. Hota, "Synthesis of ultra-fine $\alpha-\mathrm{Al}_{2} \mathrm{O}_{3}$ fibers via electrospinning method", Ceramics International, vol. 37, no. 7, (2011) pp. 2329-2333.

[21] G. Zhao, L. Xia, B. Zhong, L. Song, G. Wen, "Large-scale fast synthesis of single-crystalline alphaalumina nanotubes", Ceramics International, vol. 41, no. 2, (2015) pp. 2590-2593.

[22] P. K. Panda, S. Ramakrishna, "Electrospinning of alumina nanofibers using different precursors", Journal of Materials Science, vol. 42, no. 6, (2007) pp. 2189-2193.

[23] H. Yu, J. Guo, S. Zhu, Y. Li, Q. Zhang, M. Zhu, "Preparation of continuous alumina nanofibers via electrospinning of PAN/DMF solution", Materials Letters, vol. 74, (2012) pp. 247-249.

[24] A. -M. Azad, "Fabrication of transparent alumina $\left(\mathrm{Al}_{2} \mathrm{O}_{3}\right)$ nanofibers by electrospinning", Materials Science and Engineering: A, vol. 435-436, (2006) pp. 468-473.

[25] P. -C. Yu, R. -J. Yang, Y. -Y. Tsai, W. Sigmund, F. -S. Yen, "Growth mechanism of single-crystal $\alpha$ $\mathrm{Al}_{2} \mathrm{O}_{3}$ nanofibers fabricated by electrospinning techniques", Journal of European Ceramic Society, vol. 31, no. 5, (2011) pp. 723-731. 
International Journal of Advanced Science and Technology Vol.98 (2017) 